\title{
Klikspaan boterspaan, zwartsparen voorgoed van de baan?
}

\author{
Het oordeel van de Hoge Raad in de tipgeverszaak in de context \\ van toezicht door en op de Nederlandse belastingdienst
}

\section{Claire Hofman}

\section{$1 \quad$ Inleiding}

De Nederlandse fiscus draagt, als zelfstandig controleorgaan, de niet te onderschatten verantwoordelijkheid de landelijke schatkist op een eerlijke wijze te vullen. Iedereen dient zijn steentje bij te dragen en hiertoe heeft de inspecteur bepaalde bevoegdheden toebedeeld gekregen, die voornamelijk te vinden zijn in de Algemene Wet inzake Rijksbelastingen (AWR). ${ }^{1}$ Deze bevoegdheden leiden in de regel tot informatieverplichtingen voor belastingplichtigen ${ }^{2}$ en worden veelal als controlebevoegdheden aangeduid.

Het toezicht dat de fiscus houdt, staat sinds 2005 in het teken van transparantie. Belastingplichtigen en fiscus spreken in convenanten af om openheid van zaken te geven en met elkaar te overleggen. Eerder voorspelde De Bont dat de Belastingdienst zich in deze nieuwe vorm van horizontaal toezicht (HT) steeds meer zou opstellen als toezichthouder, in plaats van als zelfstandig controleorgaan. ${ }^{3}$ Onze Hollandse overlegcultuur ten spijt: belastingplichtigen dienen in de fase van controle in principe medewerking te verlenen, HT doet niets af aan de wettelijke informatieverplichtingen.

Ondanks deze verplichtingen ontsnappen sommige belastingplichtigen aan het toeziend oog van de fiscus, en omdat veel overtredingen van bestuurswetgeving 4 niet tot directe slachtoffers leiden, komen deze niet via een aangifte aan het licht. Streng toezicht op naleving van wet- en regelgeving is voor de fiscus dus evident om zicht te krijgen op mogelijke overtredingen en om te kunnen sanctioneren. Waaruit bestaat dit strenge toezicht anno nu? Waar fiscale fraude zich al sinds jaar en dag kenmerkt door het misleiden van de fiscus via het verstrekken van onvolledige of onjuiste informatie, is een onmiskenbare trend in toezichtland, die juist vanwege het karakter van fiscale fraude heel gemakkelijk ingebed kan wor-

1 Art. 11 AWR.

2 Bijvoorbeeld de verplichtingen ten dienste van de belastingheffing, afdeling 2 van hoofdstuk 8 van de AWR.

3 G.J.M.E. de Bont, Trends in controleland, Het register 2012, nr. 4, redactioneel.

4 Waaronder het fiscale. 
den in de fiscale wereld (ik verwijs naar het al genoemde HT), die van openheid en transparantie. ${ }^{5}$ In toenemende mate worden allerlei betrokkenen gestimuleerd, al dan niet geheime, informatie door te geven ten behoeve van de waarheidsvinding.

Voor wat betreft het verraden van geheimen onderscheidt men klikkers en klokkenluiders, waarbij een klokkenluider informatie openbaart over de organisatie waaraan hij verbonden is of was, dat openlijk doet en beëindiging van de misstand beoogt. ${ }^{6}$ Een verklikker daarentegen, hult zich bij het overbrengen van zijn informatie betreffende misstanden in anonimiteit: het is onduidelijk wat hij beoogt en ook waarom hij anoniem wil blijven. ${ }^{7}$

Verklikkers krijgen meer en meer de ruimte om bij te dragen aan de waarheidsvinding. Zo zijn er allerlei mogelijkheden voor de gewone burger om anoniem misstanden te melden ${ }^{8}$ (hierover later meer). Voorts is klikken ${ }^{9}$ voor instellingen als bedoeld in de Wet ter voorkoming van Witwassen en Financiering van Terrorisme (WWFT), waaronder de fiscale dienstverlener, zelfs verplicht. De toenemende controle op WWFT-naleving door verschillende toezichthouders (in het geval van de fiscalist: door het Bureau Financieel Toezicht (BFT)), moet het aantal meldingen van ongebruikelijke transacties bij de Financiële Inlichtingen Eenheid een boost geven. ${ }^{10}$ Bovendien heeft de Rijksdienst voor Identiteitsgegevens ${ }^{11}$ in maart van dit jaar een besluit gepubliceerd op grond waarvan persoonsgegevens uit de Basisregistratie Personen op verzoek worden verstrekt aan het BFT. ${ }^{12}$ Men zal dus spreken, en men zal delen, met als consequentie dat men zich anderzijds zo min mogelijk zal verschonen.

In deze bijdrage bespreek ik een uitspraak van de Hoge Raad, waarin een verklikker waardevol bleek en wiens motief vermoedelijk hand in hand ging met de toegekende beloning. De Belastingdienst maakte tegen betaling gebruik van informatie van een geheime tipgever om na te vorderen bij anderen. Waar deze tipgever anonimiteit werd beloofd, bleef Judas Iskariot, die Jezus Christus lang geleden in ruil voor dertig zilverlingen verraadde, niet anoniem, met als gevolg dat hij in de christelijke wereld als het symbool van onbetrouwbaarheid werd gezien. ${ }^{13}$ Of Judas Iskariot vervolgens aanspraak kon maken op geregelde bescherming is mij niet bekend. Omdat klokkenluiders en verklikkers vandaag de dag van overheids-

5 E. Scholtes, Transparantie, icoon van een dolende overheid, Den Haag: Boom Lemma uitgevers 2012.

6 Over (de effectiviteit of bescherming van) klokkenluiders gaat deze bijdrage uitdrukkelijk niet.

7 E. Lissenberg, Klokkenluiders en verklikkers, afscheidsrede Universiteit van Amsterdam, 2008 (zie <http://dare.uva.nl/document/2/67066>, geraadpleegd 22 mei 2015).

8 Meld misdaad anoniem of Opsporing verzocht, maar zie ook deze tipgeverszaak waarin bij de fiscus wordt geklikt.

9 In de wet spreekt men van een meldplicht, maar volgens de definities die Lissenberg hanteert, geldt de term 'melden' voor interne situaties.

10 J.A. Booij, De WWFT voor advocaten en belastingadviseurs, TFB 2014/03.

11 Onderdeel van het ministerie van Binnenlandse Zaken en Koninkrijksrelaties.

12 Autorisatiebesluit Bureau Financieel Toezicht, Rijksdienst voor Identiteitsgegevens, Stcrt. 2016, 8876.

13 Zie bijvoorbeeld het Evangelie van Matteüs, 26:47-51. 
wege worden gestimuleerd te klikken, is de vraag naar (wettelijke) bescherming wel relevant. Voor klokkenluiders geldt (aangezien zij niet anoniem melden) dat bescherming achteraf noodzakelijk is, ${ }^{14}$ maar voor verklikkers geldt in eerste instantie dat een garantie op anonimiteit evident is. Hoewel het gebruik van de tipgever in de hierna te bespreken zaak door het hof onrechtmatig werd geacht, koos de Hoge Raad voor anonimiteit van de tipgever en benadrukte hij daarmee het belang van bescherming van de privacy van verklikkers.

\section{HR 18 december 2015, ECLI:NL:HR:2015:3604}

Van Judas uit de christelijke oudheid naar een tipgever die zich in 2009 bij de toenmalig staatssecretaris van Financiën meldde. Deze tipgever had gedetailleerde informatie over onder meer 69 belastingplichtigen met een bankrekening bij Rabobank Luxemburg S.A. Net als Judas sloot hij een overeenkomst en deze tipgever deed dat met niemand minder dan de Staat der Nederlanden. ${ }^{15}$ En net als Judas sprak de tipgever af dat hij een geldbedrag zou ontvangen, in ruil voor de informatie. Geen zilverlingen, maar euro's waarvan het aantal afhankelijk was van de extra opbrengst die als gevolg van de verstrekte informatie bij de Nederlandse schatkist binnen zou komen.

Op 6 juni 2013 behandelde de Rechtbank Gelderland een zaak van een van deze verraden belastingplichtigen. Deze zaak staat nu, ongeveer twee jaar later, bekend als de opzienbarende 'tipgeverszaak'. Het betreft navorderingsaanslagen inkomstenbelasting van een erflater die altijd ontkende buitenlandse bankrekeningen te hebben. Nog voor zijn overlijden in 2012 gaven de erven het bestaan van die bankrekeningen toe. De Rechtbank Gelderland oordeelde ${ }^{16}$ dat de naam van de tipgever niet hoefde te worden geopenbaard en verbond geen gevolgen aan de weigering van de Inspecteur om door belanghebbende gevraagde ongeschoonde

14 Zie voetnoot 6: over (de effectiviteit of bescherming van) klokkenluiders gaat deze bijdrage uitdrukkelijk niet.

15 Waarover de staatssecretaris van Financiën de Tweede Kamer informeerde bij brief van 30 oktober 2009, nr. DGB2009/5737U.

16 E.e.a. overigens na een uitspraak van de voorzieningenrechter - Rb. Arnhem 22 maart 2011, nr. 11/003222 en 11/00324, ECLI:NL:RBARN:2011:BP8580, NTFR 2011/1374 - waarin de Inspecteur op de vingers werd getikt voor het niet ter inzage leggen van stukken in de bezwaarfase conform art. 7:4 lid 2 Awb, en na een uitspraak van de geheimhoudingskamer van de Rechtbank Arnhem - Rb. Arnhem 7 februari 2012, nr. 11/01635 en 11/01636, ECLI:NL:RBARN:2012:BV2902, NTFR 2012/1165, die ook oordeelde dat de Inspecteur stukken diende over te leggen; de Inspecteur had het oordeel van de voorzieningenrechter aan zijn laars gelapt. 
versies ${ }^{17}$ van de stukken met betrekking tot die tipgever over te leggen. ${ }^{18}$ Immers, de door de tipgever verstrekte gegevens waren voor de beoordeling van het geschil niet nodig (de erven hadden het bestaan van de bankrekening toegegeven) en het was niet aannemelijk gemaakt dat belanghebbenden door de weigering van de Inspecteur in hun belangen waren geschaad. ${ }^{19}$

Noemenswaardig in dit verband is het feit dat de geheimhoudingskamer van de Rechtbank Arnhem de ongeschoonde stukken al eerder (uitspraak 7 februari 2012) beoordeelde. Deze rechtbank moest door middel van een tussenuitspraak beslissen of de weigering door de Inspecteur om alle stukken in ongeschoonde vorm te verstrekken, gerechtvaardigd was. De Inspecteur werd in deze procedure verplicht de stukken, waaronder de overeenkomst tussen de tipgever en de Staat, te openbaren.

Volgens de geheimhoudingskamer was namelijk niet aannemelijk gemaakt dat de mogelijkheid van bedreiging van de tipgever aanwezig was, en daarnaast werd een onlosmakelijk verband tussen de persoon van de tipgever en de door hem verstrekte informatie geconstateerd. ${ }^{20}$

In lijn met de geheimhoudingskamer van de Rechtbank Arnhem van 7 februari 2012, maar in tegenstelling tot de uitspraak van de Rechtbank Gelderland van 6 juni 2013, acht het Gerechtshof Arnhem-Leeuwarden begin februari 2015 geen gewichtige redenen aanwezig om de naam van de tipgever geheim te houden. ${ }^{21}$ Ter ondersteuning van zijn oordeel noemt het hof vooral de vraag naar de rechtmatigheid van de verkrijging van het bewijs. Voor wat betreft onrechtmatig verkregen bewijs geldt een aloud criterium, ${ }^{22}$ dat belanghebbenden in hoger beroep dan ook hebben aangevoerd: het gebruik van een tipgever, tegen vergoeding, 'druischt zozeer in' tegen hetgeen van een behoorlijk handelende overheid mag worden verwacht, dat dit bewijs moet worden uitgesloten. Juist vanwege het feit dat de identiteit van de tipgever geheim bleef, kon hij niet als getuige worden gehoord, en konden belanghebbenden niet nagaan hoe hij aan zijn informatie was gekomen (of tegen de FIOD-ECD heeft gezegd te zijn gekomen). Het is voor belanghebbenden dus onmogelijk het 'zozeer indruischt-criterium' nader te onderbouwen. $\mathrm{Al}$ met al wordt de volhardende weigering van de Inspecteur door

17 Van belang voor onderhavige zaak is dat stukken in hun originele vorm tot de op de zaak betrekking hebbende stukken zoals bedoeld in art. 8:42 Awb behoren. Een verzoek om uitsluitend in geanonimiseerde vorm in te brengen, dient dus beoordeeld te worden in het kader van art. 8:29 Awb.

18 Dit is mogelijk op grond van art. 8:31 Awb en het oordeel is in lijn met de conclusie van A-G Wattel van 24 mei 2013, nr. 12/03379, NTFR 2013/1136, waarin aan de uitspraak van de geheimhoudingskamer werd gerefereerd, en waarin Wattel stelt dat bestuursorganen ervoor kunnen kiezen niet aan hun overleggingsplicht te voldoen, ondanks rechterlijke 'telichtbevinding' van hun gronden daarvoor, mits zij de gevolgen daarvan voor hun procespositie aanvaarden.

19 Rb. Gelderland 6 juni 2013, ECLI:NL:RBGEL:2013:CA1888, NTFR 2013/1554.

20 Rb. Arnhem 7 februari 2012, nr. 11/01635 en 11/01636, ECLI:NL:RBARN:2012:BV2902, NTFR 2012/1165.

21 Gerechtshof Arnhem-Leeuwarden 3 februari 2015, ECLI:NL:GHARL:2015:645.

22 Dat door de Hoge Raad bij uitspraak van 20 maart 2015, ECLI:NL:HR:2015:643 nog steeds als leidend wordt bestempeld. 
het hof onrechtmatig geacht en dientengevolge worden de navorderingsaanslagen van belanghebbenden, die in hun procesbelangen zijn geschaad, vernietigd.

Naast het feit dat de naam van de essentiële getuige om wie het hier gaat een hele tijd angstvallig geheim wordt gehouden, speelt de consequentie hiervan, namelijk dat belanghebbenden niet anders kunnen dan trachten de waarheid op een andere manier op tafel te krijgen, een belangrijke rol. Belanghebbenden geven bij het hof aan dat zij de andere verbalisanten, en wel alle betrokken ambtenaren van de Belastingdienst en de FIOD-ECD, ${ }^{23}$ willen horen over de gang van zaken. Echter, omdat ook de namen van deze personen niet bekend zijn gemaakt, is het onmogelijk deze getuigen op te roepen. Hiermee schendt de Inspecteur, naar het oordeel van het hof, het beginsel van equality of arms.

Ter zitting is uiteindelijk aan twee belastingambtenaren, die wel door de Inspecteur waren meegebracht, door belanghebbenden gevraagd naar de naam van de tipgever. De twee ambtenaren houden hun mond en beroepen zich op het verschoningsrecht van artikel 67 AWR. ${ }^{24}$ Het hof wijst dit beroep af, omdat belastingambtenaren geen algemeen verschoningsrecht hebben: het is aan de rechter om per gestelde vraag te bepalen of beantwoording naar waarheid kan geschieden, zonder dat daarbij geheimen die verborgen dienen te blijven, worden prijsgegeven. Vervolgens geven de getuigen te kennen dat ze geen mededeling mogen doen op instructie van het ministerie van Financiën, waarop bij het hof de verdenking van beïnvloeding van deze twee getuigen rees, en de president van het hof strafrechtelijke aangifte doet tegen de onbekende instructeurs. ${ }^{25}$

Advocaat-generaal IJzerman (A-G) schrijft drie conclusies over deze spraakmakende tipgeverszaak. ${ }^{26}$ In zijn tweede conclusie heeft de A-G ambtshalve ${ }^{27}$ geconcludeerd dat de getuigen niet verplicht waren om desgevraagd de naam van de tipgever bekend te maken. Volgens IJzerman had het hof moeten doorvragen naar de gevaren voor de tipgever. Verder meent de A-G dat de getuigen functioneel te vereenzelvigen waren met de Inspecteur. Er mag daarom een link worden gelegd tussen zijn weigering stukken over te leggen en het zwijgen van de getuigen.

24 Lid 1: Het is een ieder verboden hetgeen hem uit of in verband met enige werkzaamheid bij de uitvoering van de belastingwet over de persoon of zaken van een ander blijkt of wordt meegedeeld, verder bekend te maken dan noodzakelijk is voor de uitvoering van de belastingwet of voor de invordering van enige rijksbelasting als bedoeld in de Invorderingswet 1990 (geheimhoudingsplicht).

25 Brief van 11 november 2014, kenmerk FW/MD 111114, NTFR 2014/1894.

26 Conclusie 29 april 2015, ECLI:NL:PHR:2015:546, waarin de A-G met name processuele kwesties behandelt: hij komt tot niet-ontvankelijkheid van de getuigen omdat ze in cassatie komen tegen een tussenuitspraak in plaats van tegen een einduitspraak, en omdat getuigen niet in cassatie kunnen komen. Conclusie 21 augustus 2015, ECLI:NL:PHR:2015:1477 en Conclusie 21 augustus 2015, ECLI:NL:PHR:2015:1480.

Hij concludeert eerder al tot niet-ontvankelijkheid, zie voetnoot 10 . 
Verder meent de A-G dat, indien de fiscus ervoor kiest om een anonieme tipgever te gebruiken, en de rechterlijke controle ertoe leidt dat zijn naam bekend moet worden gemaakt, de rechter aan volhardende weigering gevolgen kan verbinden die haar geraden voorkomen. ${ }^{28}$ De verdere gevolgen van het niet geven van de naam hadden in dat kader hun beslag moeten krijgen. De Hoge Raad oordeelt in lijn met zijn advies dat de tipgever anoniem mag blijven. ${ }^{29}$

Waar de Hoge Raad geen weet van had, is het later aan het licht gekomen feit dat in de tipgeversovereenkomst vastgelegd is dat de Belastingdienst geen garantie kon geven voor wat betreft het waarborgen van de anonimiteit, en dat de tipgever desondanks bereid was de informatie, tegen vergoeding, te verstrekken. Hier kom ik later op terug.

\section{Privacy vs. fair trial in fiscale tipgeverszaken}

Hoe moet in een fiscale tipgeverszaak nu worden omgegaan met schriftelijke stukken, ten aanzien waarvan de Inspecteur blijft weigeren ongeschoonde versies over te leggen? Voor een tipgever in een zwartspaarderszaak kan vanzelfsprekend relevant zijn dat zijn identiteit geheim blijft. Op grond van artikel 8:29 Algemene wet bestuursrecht (Awb) mag de Inspecteur dan ook inbreuk maken op het principe uit artikel 8:42 Awb, dat alle op de zaak betrekking hebbende stukken, dat wil zeggen stukken die van belang zijn geweest voor de besluitvorming van de zaak, ${ }^{30}$ aan de rechter moeten worden verstrekt. ${ }^{31} \mathrm{Als}$ de inspecteur een beroep doet op artikel 8:29 Awb, dan is het aan de rechter om te bepalen of er gewichtige redenen zijn om een volledige weigering van inbreng of een beperkte kennisneming van stukken te rechtvaardigen. ${ }^{32}$ Als die er niet zijn en de inspecteur blijft weigeren openheid van zaken te geven, dan kan de rechtbank op grond van artikel 8:31 Awb aan deze weigering de gevolgen verbinden die haar geraden voorkomen. ${ }^{33}$

28 Indien een partij niet voldoet aan de verplichting te verschijnen, inlichtingen te geven, stukken over te leggen of mee te werken aan een onderzoek als bedoeld in art. 8:47 lid 1 Awb, kan de bestuursrechter daaruit de gevolgtrekkingen maken die hem geraden voorkomen.

29 HR 18 december 2015, ECLI:NL:HR:2015:3604.

30 Sinds de inwerkingtreding van het Besluit Beroep in Belastingzaken per 1 januari 2012 kennen we deze Awb-conforme uitleg.

31 In beginsel is het de Inspecteur die bepaalt wat de op de zaak betrekking hebbende stukken zijn, maar als een belanghebbende kennis heeft van het bestaan van een stuk, en dit wil inzien, dan geldt de inbrengverplichting van art. 8:42 Awb.

32 Bij een volledige weigering wordt de gevraagde informatie in het geheel niet verstrekt (ook niet aan de bestuursrechter om inhoudelijk te beoordelen of de volledige weigering gerechtvaardigd is), bij een beperkte kennisneming wordt de gevraagde informatie uitsluitend aan de rechtbank verstrekt.

33 De rechtbank beslist binnen vier weken door middel van een tussenuitspraak. De tussenuitspraak van de rechtbank is in hoger beroep niet meer van toepassing. Als de stukken na een afgewezen verzoek ex art. 8:29 Awb nog steeds niet worden ingebracht, moet dus een nieuw verzoek worden gedaan. 
Hoe verhoudt bovenstaande zich tot de fiscale geheimhoudingsplicht ${ }^{34}$ van artikel 67 AWR? Aan dit artikel ligt de gedachte ten grondslag dat belastingplichtigen erop moeten kunnen vertrouwen dat verstrekte informatie enkel voor het uitvoeren van de belastingwetgeving wordt gebruikt. In bepaalde gevallen houdt artikel 67 AWR dan ook een verschoningsrecht voor belastingambtenaren in: het gaat om alle informatie die onder de geheimhoudingsplicht valt.

Kortom: op grond van artikel 8:42 Awb dient de inspecteur alle stukken in ongeschoonde vorm in het geding te brengen, tenzij er gewichtige redenen als bedoeld in artikel 8:29 Awb zijn die tot geheimhouding strekken. Geheimhouding staat ook centraal in artikel 67 AWR en in het verlengde hiervan bestaat een verschoningsrecht. In een obiter dictum (r.o. 2.7.2) oordeelt de Hoge Raad in onderhavige zaak dat een getuige die tot dezelfde organisatie behoort als de procespartij die volhardt in haar weigering ongeschoonde stukken over te leggen, op grond van artikel 8:29 Awb niet gedwongen kan worden de gegevens te verstrekken die deze procespartij niet wil verstrekken en zich in dit verband beroept op artikel 67 AWR. Op deze manier is de link tussen de artikelen 8:29 Awb en 67 AWR gelegd.

$\mathrm{Nu}$ het recht op kennisneming van bewijsmateriaal niet absoluut is, rijst vervolgens de vraag welke belangen in het kader van artikel 8:29 Awb moeten worden afgewogen. Als gewichtige redenen kunnen onder andere worden genoemd het belang van privacy, het belang van een effectieve controle(strategie) en ongehinderde opsporing. Anderzijds is van groot belang het recht op een fair trial, als bedoeld in artikel 6 Europees Verdrag voor de Rechten van de Mens (EVRM). Gedacht kan worden aan het bepalen van de processtrategie en voor partijen is essentieel dat zij in het kader van hoor- en wederhoor als gelijken tegenover elkaar kunnen staan (equality of arms). Het argument van de Belastingdienst, namelijk de bescherming van de persoonlijke sfeer van de tipgever, bleek in deze zaak uiteindelijk het zwaarst te wegen. Dit is opmerkelijk, gezien het al eerder genoemde feit dat de tipgever bereid bleek, bij gebrek aan garantie op anonimiteit, desondanks te verklaren.

\section{De rol van toezicht in het fiscale recht}

Hoewel iemand als Judas van onschatbare waarde kan zijn, behoort het gebruik van tipgevers officieel niet tot de controlebevoegdheden van de inspecteur. Er lijkt behoefte te zijn aan een moderne vorm van toezicht, omdat de traditionele controlebevoegdheden niet meer voldoen. In deze context kan de sfeerovergang controle en opsporing voorts niet onbesproken blijven. Het staat vast dat artikel 6 EVRM en het daarin verwoorde recht op een eerlijk proces, onverkort van toepassing is op zaken waarin tipgevers de fiscus bedienen en waarin het uiteindelijk tot een gerechtelijk geschil komt. Immers, tipgevers zullen inlichtingen verstrekken over belastingplichtigen die bewust informatie achterhouden. Als het uitein- 
delijk tot een sanctie komt, zal dit een bestuurlijke vergrijpboete ${ }^{35}$ of een strafrechtelijke boete ${ }^{36}$ betreffen. Beide kwalificeren als criminal charge in de zin van artikel 6 EVRM, en dus dient sprake te zijn van een eerlijk proces.

Was er in deze tipgeverszaak sprake van een eerlijk proces? Uiteindelijk is de discussie te herleiden naar doel en strekking van artikel 8:29 Awb. Immers: omdat de Inspecteur op grond van dit artikel weigerde stukken te overhandigen, en de getuigen functioneel te vereenzelvigen waren met de Inspecteur, werd hun toegestaan te zwijgen, en leeft de Judas uit onze tipgeverszaak nog steeds in anonimiteit. In het licht van een eerlijk proces zou men kunnen stellen dat het verdedigingsbelang in dezen (te) zwaar is geraakt. Met de geheimhoudingskamer van de Rechtbank Arnhem en met het Hof Arnhem-Leeuwarden ben ik van mening dat er concrete aanwijzingen voor represailles voor de tipgever hadden dienen te worden aangetoond. Aan de weigerachtige houding van de Inspecteur zou naar mijn mening een adequaat gevolg moeten worden verbonden, om te voorkomen dat de prikkel om aan artikel 8:42 Awb te voldoen verdwijnt.

Het feit dat de Inspecteur desondanks kon persisteren in zijn weigering doet de vraag rijzen naar de effectiviteit van toezicht op de fiscus en de werking van de trias politica. Zowel de A-G als de Hoge Raad meent dat in toezicht is voorzien; de rechter kan op grond van artikel 8:31 Awb immers gevolgen verbinden aan schending van het gebod om stukken te overhandigen. Checks (\& balances) zijn we dus niet uit het oog verloren. Het feit dat een belangenafweging op grond van artikel 8:31 Awb heeft plaatsgevonden juich ik vanzelfsprekend toe. Echter, binnen de discretionaire bevoegdheid die de rechter heeft, zou artikel 6 EVRM naar mijn mening meer recht moeten worden gedaan. Het feit dat de Rechtbank Gelderland geen enkel gevolg aan de schending van artikel 8:29 Awb verbond, werd door Thijssen een anticlimax genoemd. ${ }^{37}$ Het argument dat de vergrijpboeten waren vervallen door het overlijden van erflater, waardoor artikel 6 EVRM geen toepassing meer zou vinden op dit geval, zie ik als een nog grotere anticlimax. Ik ben dan benieuwd naar de afloop van een geval waarin vergrijpboeten nog staan.

Voorts kan ik het niet laten de suggestieve vraag te stellen of er daadwerkelijk sprake is (of beter gezegd: kan zijn) van checks \& balances, als rechters (tot aan de Hoge Raad) worden misleid. In de besproken tipgeverszaak zagen de rechters immers alleen zwart gelakte versies van de tipgeversovereenkomst, waardoor de raadsheren niet wisten dat de tipgever ondanks gebrek aan gegarandeerde anonimiteit bereid was te klikken. Van een goed functionerende rechtstaat is geen sprake, al helemaal niet als medewerkers van de Belastingdienst onder ede het tegenovergestelde verklaren. Zoals Paul Bovend'Eert in Nieuwsuur ${ }^{38}$ verklaarde: we zouden op zijn minst een integriteitsschending kunnen constateren. 
De klok luiden of anoniem misdaad melden: juist in de financiële en fiscale wereld, waarin verborgen criminaliteit de boventoon voert, lijken signalen en aanwijzingen van binnenuit of van derden steeds vaker waardevol. De in deze Notenkraker besproken zaak en de opschudding die hierdoor veroorzaakt werd in de media, duidt op de dilemma's die met deze moderne vormen van toezicht, die zich als 'klikken' laat samenvatten, gepaard gaan.

Enkele van deze dilemma's kaartte ik in deze bijdrage aan en ik sluit af met de vraag naar het nut van de fiscaletipgeversdiscussie op dit moment. Met het toenemende gemak waarmee internationaal gegevens (gaan) worden uitgewisseld, lijken de mogelijkheden toezicht te houden (en op te sporen) immers in aanzienlijke mate vereenvoudigd. Relevante(re) vraag met het oog op de toekomst is dus in hoeverre dit grensoverschrijdend toezicht met waarborgen is omkleed.

Voor inkeerders geldt per 1 juli van dit jaar een boete van 120 procent. Of nu een tipgever of de buitenlandse belastingdienst fungeert als klikspaan: zwartsparen lijkt voorgoed van de baan. 